\title{
Tecendo a rede assistencial em \\ saúde mental com a ferramenta matricial
}

\author{
I ${ }^{1}$ Fernando Sérgio Pereira de Sousa, ${ }^{2}$ Maria Salete Bessa Jorge, ${ }^{3}$ Mardênia Gomes \\ Ferreira Vasconcelos, ${ }^{4}$ Márcia Maria Mont'alverne de Barros, ${ }^{5}$ Paulo Henrique Dias \\ Quinderé, ${ }^{6}$ Luciana Gurgel Farias Gondim I
}

Resumo: Objetivou-se analisar o matriciamento como ferramenta articuladora da rede de atenção em saúde mental. Trata-se de uma pesquisa de natureza qualitativa, realizada no Nordeste brasileiro, no período de março a abril de 2010. Utilizaram-se para a coleta das informações a entrevista semiestruturada e a observação sistemática. Como participantes da pesquisa, incluíram-se 47 profissionais de saúde da Estratégia Saúde da Família e dos Centros de Atenção Psicossocial, distribuídos em dois grupos. Os dados foram organizados e analisados pelos pressupostos da análise de conteúdo articulando o teórico com o empírico. Em cumprimento ao exigido, o estudo foi submetido à análise do Comitê de Ética em Pesquisa adequando-se às normas da pesquisa envolvendo seres humanos. Segundo os resultados evidenciaram, o apoio matricial é uma estratégia potente, pois possibilita a construção de um sistema articulado em rede no SUS, não limitado às fronteiras de um dado serviço. Interconectado por uma equipe de referência, que mobiliza diversos atores para lidar com o andamento do caso, o apoio matricial sinaliza os caminhos que viabilizam a conexão de redes de cuidados em saúde mental.

> Palavras-chave: Atenção primária; rede de cuidados continuados de saúde; saúde mental.
1 Enfermeiro. Mestre em Saúde Pública da Universidade Estadual do Ceará (UECE). Membro do Grupo de Pesquisa Saúde Mental, Família, Práticas de Saúde e Enfermagem (GRUPSFE). Endereço eletrônico: fernando_sergio_1@ hotmail.com

2 Enfermeira. Doutora em Enfermagem pela Escola de Enfermagem de Ribeirão Preto/ USP. Professora Titular da UECE. Pesquisadora 1C-CNPq. Docente do Mestrado em Saúde Pública da UECE, do Mestrado em Cuidados Clínicos em Saúde da UECE e do Doutorado em Saúde Coletiva da UECE/UFC. Líder do Grupo de Pesquisa GRUPSFE. Endereço eletrônico: maria.salete.jorge@ gmail.com

${ }^{3}$ Enfermeira. Mestranda em Saúde Pública da UECE. Membro do GRUPSFE. Endereço eletrônico: mardeniagomes@yahoo.com.br

${ }^{4}$ Terapeuta Ocupacional. Doutoranda em Saúde Coletiva com Associação Ampla UECE/ UFC/UNIFOR. Mestre em Saúde Pública pela UECE. Membro do GRUPSFE. Endereço eletrônico: marcia_mab@hotmail.com

5 Psicólogo. Doutorando em Saúde Coletiva com Associação Ampla UECE/UFC/UNIFOR. Mestre em Saúde Pública pela UECE. Membro do GRUPSFE. Endereço eletrônico: pauloquindere@hotmail.com

${ }^{6}$ Graduanda de Serviço Social da UECE. Membro do GRUPSFE. Endereço eletrônico: lucianagfg@ hotmail.com

Recebido em: 15/03/2011 Aprovado em: 11/09/2011. 


\section{Introdução}

As ações de saúde mental devem obedecer ao modelo de redes de cuidado de base territorial e atuação transversal com outras políticas específicas voltadas ao estabelecimento de vínculos e acolhimento. Nesse sentido, o arranjo organizacional do apoio matricial (AM) ou matriciamento, formulado por Campos (1999), surge com o objetivo de aumentar o grau de resolubilidade das ações de saúde. Esse arranjo propõe uma reformulação no modo de organização dos serviços e relações horizontais entre as especialidades que passam a oferecer apoio técnico horizontal às equipes interdisciplinares de atenção básica, favorecendo assim a conexão em rede.

É nessa linha de entendimento que a atual política de saúde mental no Brasil, conformada aos pressupostos da reforma psiquiátrica, recomenda a progressiva substituição dos hospitais psiquiátricos. Tal substituição se dará por uma rede de serviços de atenção em saúde mental composta por centros de atenção psicossocial (CAPS); ambulatórios de saúde mental; residências terapêuticas; centros de convivência e cultura; atendimento em saúde mental na rede básica de saúde por meio do matriciamento (BEZERRA; DIMENSTEIN, 2008). A atenção em saúde mental pode mesmo ser desenvolvida, como proposto pelo Ministério da Saúde, dentro de uma rede articulada de cuidados (BRASIL, 2003).

Conforme se compreende, a organização em rede de serviços rompe com o modelo hierárquico tradicional fundamentado em níveis de complexidade, que impossibilita a flexibilização e a articulação das ações, restringindo a assistência e organizando a demanda de acordo com as necessidades do sistema, e não conforme as necessidades dos usuários, principais protagonistas aos quais os serviços se destinam. Nesse sentido, como infere Franco (2006), todo cuidado em saúde sempre se produz em rede, evidenciada mediante as articulações percebíveis entre as unidades nos seus diversos níveis, entre as equipes, os saberes, as práticas e as subjetividades, remetendo à ideia de imanência e de interdependência.

Ao se fomentar a discussão, pode-se afirmar que, possivelmente, os serviços de saúde mental subvertem a lógica da hierarquização e se organizam agregando os diferentes níveis de atenção à saúde. Fazem, portanto, surgir expressivas questôes na própria organização do Sistema Único de Saúde (SUS). Podem atuar em nível de atenção básica, no acompanhamento e no AM de casos nas unidades básicas de saúde. Além disso, fazem atendimento especializado dos casos de transtornos 
mentais e são responsáveis pelo acompanhamento dos pacientes nas unidades de

internação nos hospitais gerais. Perpassam, assim, os níveis de complexidade da rede de saúde (ONOCKO-CAMPOS; FURTADO, 2006).

Consoante o citado, a estratégia do AM ganha potência a partir da constatação segundo a qual a reforma psiquiátrica não pode ir adiante com seus inovadores propósitos se a atenção à saúde mental se restringe apenas aos serviços especializados nesse campo. Logo, não basta empenhar-se somente na rede substitutiva; é preciso estender o cuidado em saúde mental para todos os níveis de assistência da rede de saúde (DIMENSTEIN et al., 2009).

O matriciamento é um arranjo institucional recentemente incorporado pelo Ministério da Saúde (BRASIL, 2003) como estratégia de gestão para a construção de uma rede ampla de cuidados em saúde mental, desviando a lógica de encaminhamentos indiscriminados para uma lógica da corresponsabilização. Ademais, visa produzir maior resolubilidade à assistência em saúde mental na atenção primária. Nessa perspectiva, como relata Inpes (2007), algumas características foram atribuídas à prática da saúde mental na atenção primária, entre elas: assegurar o bem-estar da comunidade e do indivíduo; privilegiar as ações preventivas, individuais e coletivas; alocar os programas de saúde mental em diferentes serviços de atenção primária, formando uma rede de suporte e cuidados; e, por fim, utilizar novas estratégias de abordagem em saúde.

De acordo com Campos e Domitti (2007), o termo "matricial" indica uma mudança radical de posição do especialista em relação ao profissional que demanda seu apoio. Portanto, profissionais de referência e especialistas devem manter uma relação horizontal, e não apenas vertical, como recomenda a tradição dos sistemas de saúde. Isso simboliza a quebra de rigidez provocada pela hierarquização dos níveis de complexidade de saúde e pela diferenciação de autoridade entre os profissionais, fatores marcadamente presentes na organização clássica dos serviços. Já o termo "apoio" sugere uma maneira para se operar mediante a construção de várias linhas de transversalidade numa relação entre referência e especialista baseada em procedimentos dialógicos.

Além disso, define-se essa estratégia matricial como momentos relacionais nos quais se estabelece troca de saberes entre os profissionais de diferentes serviços de atenção envolvidos no cuidado dos usuários, com vistas a garantir às equipes das unidades básicas de saúde e unidades referenciadas a responsabilidade pela 
condução das ações desencadeadas no processo de assistência. Desse modo, ampliam-se as possibilidades de construção de vínculo entre profissionais e usuários, e também se assegura a integralidade da atenção em todo o sistema de saúde (FIGUEIREDO, 2006).

Por responsabilidade de condução, entende-se a tarefa de encarregar-se da atenção ao longo do tempo, ou seja, de maneira longitudinal, à semelhança do preconizado para as equipes da atenção primária (STARFIELD, 1992). Com o apoio matricial, torna-se possível distinguir as situaçoos individuais e sociais, comuns à vida cotidiana, que podem ser acolhidas pela equipe de referência e por outros recursos socioassistenciais do entorno daquelas demandas que exijam uma atenção especializada da saúde mental, a ser ofertada na própria unidade ou, de acordo com o risco e a gravidade, pelo CAPS da região de abrangência. Isso permite evitar práticas que levem à "psiquiatrização" e à "medicalização" do sofrimento e, paralelamente, também permite promover a equidade e o acesso, garantindo níveis terapêuticos de acordo com as vulnerabilidades e potencialidades de cada usuário. Dessa forma, o AM favorece a construção de novos arranjos de atenção em resposta às diferentes necessidades dos usuários e a articulação entre os profissionais na formulação de projetos terapêuticos planejados para cada situação singular (FIGUEIREDO; ONOCKO-CAMPOS, 2009).

Contudo, como afirma Quinderé (2008), embora a produção de estudos sobre o tema da saúde mental tenha crescido ao longo dos anos, ainda são poucos os destinados a compreender o funcionamento dos serviços de saúde mental em rede e sua articulação com os demais componentes do sistema de saúde. Permanece, portanto, uma lacuna nesse campo, principalmente no tocante à maneira como os serviços têm se organizado em relação à sua concepção de rede.

O objeto deste estudo ${ }^{1}$ mostra-se relevante e original, particularmente por ser o AM um dispositivo articulador de um conjunto de estratégias fundamentais no processo de construção e de transformação da assistência em saúde mental em rede. Por ser o AM um arranjo inovador e em fase de implementação no SUS, é de grande importância a formulação de propostas instigadoras de análise dessa experiência. Nesse prisma, o artigo em elaboração tem como objetivo analisar o matriciamento como ferramenta articuladora da rede de atenção em saúde mental. Com a realização do estudo, espera-se contribuir para a ampliação das 
discussões sobre essa problemática e colaborar para a construção de uma prática que valorize e fortaleça a abordagem multidisciplinar e interdisciplinar.

\section{Metodologia}

Trata-se de pesquisa com abordagem qualitativa, por constituir uma discussão aprofundada sobre a realidade social a partir de um referencial teórico-ideológico, no caso, a reforma psiquiátrica brasileira.

O estudo foi realizado em dois cenários no Nordeste do Brasil. Desse modo, o cenário I corresponde a um município com 2.505.552 habitantes, o qual possui 88 centros de saúde da família, distribuídos nas seis Secretarias Executivas Regionais (SERs), com cobertura da Estratégia Saúde da Família (ESF) de 42\% da população. No que concerne ao cenário II, este está localizado no interior do estado do Ceará, e tem uma população de 175.814 habitantes. Conta com 14 centros de saúde da família na sede e 14 centros de saúde da família nos distritos, apresentando uma cobertura de $94 \%$ da ESF.

Nos referidos cenários, a rede de serviços de saúde mental promove a interface com a atenção primária por meio do matriciamento com a participação de equipes de saúde mental e da saúde da família com foco no território. Em cada município, a rede é caracterizada por serviços substitutivos, como CAPS, residência terapêutica, leitos psiquiátricos em hospital geral, diferenciando-se, no cenário I, por serviços adicionais como as ocas comunitárias (trabalho em saúde mental preventivo e curativo, engajando elementos culturais e sociais ativos na comunidade, com ênfase no trabalho em grupo) e, no cenário II, por um ambulatório de psiquiatria.

Participaram da pesquisa os trabalhadores de saúde, responsáveis pelo matriciamento, dos diferentes cenários citados que atuam no CAPS e na ESF, no total de 47 entrevistados. Entre estes, profissionais de nível superior, assim especificados: enfermeiros, psicólogos, médicos, assistentes sociais, terapeutas ocupacionais e farmacêuticos; e de nível médio, representados pelos agentes comunitários de saúde. Tais participantes foram subdivididos em dois grupos: Grupo I - trabalhadores de saúde do CAPS; e grupo II - trabalhadores de saúde da ESF, conforme explicitado a seguir: 


\begin{tabular}{|c|c|c|c|}
\hline Grupo & Representação & Participantes & Categoria Profissional \\
\hline I & $\begin{array}{l}\text { Trabalhadores de } \\
\text { saúde do CAPS } \\
\text { (Cenários I e II) }\end{array}$ & 25 & $\begin{array}{l}\text { Enfermagem - } 06 \\
\text { Psicologia - } 04 \\
\text { Assistente Social - } 04 \\
\text { Terapeuta Ocupacional - } 04 \\
\text { Medicina - } 05 \\
\text { Farmácia - } 02\end{array}$ \\
\hline II & $\begin{array}{l}\text { Trabalhadores } \\
\text { de saúde da ESF } \\
\text { (Cenários I e II) }\end{array}$ & 22 & $\begin{array}{l}\text { Enfermagem - } 09 \\
\text { Medicina - } 05 \\
\text { Agente Comunitário - } 06 \\
\text { Dentista - } 02\end{array}$ \\
\hline
\end{tabular}

Como critério de inclusão optou-se pelos trabalhadores dos CAPS e da ESF nas seguintes condiçôes: terem integrado a equipe de apoio matricial ou de referência na prática do matriciamento, estarem vinculados há pelo menos um ano e aceitarem participar da pesquisa, após a apresentação e a assinatura do termo de consentimento livre e esclarecido.

Para a coleta das informações, utilizaram-se a entrevista semiestruturada e a observação sistemática das práticas no matriciamento. A coleta ocorreu em dois momentos: primeiramente, no período de outubro de 2009 a março de 2010 com a aproximação com os campos empíricos, validação dos roteiros de entrevista e devolução dos dados parciais coletados aos sujeitos. O segundo momento deu-se no período de junho de 2010 a outubro de 2010, com a continuação das investigações e, posteriormente, apresentação do relatório final da pesquisa aos participantes do estudo com consequentes discussões e aprofundamento da temática.

$\mathrm{Na}$ análise do material empírico, para o melhor entendimento das questôes do estudo, tomou-se como base Minayo (2008), segundo a qual o objeto de análise é a práxis social. No primeiro contato com os dados brutos, fez-se a transcrição do material gravado em audiodigital. Houve leitura do material e criação de núcleos de sentido. Em seguida, esses núcleos de sentido foram agrupados em categorias e procedeu-se à organização das informações contempladas nas entrevistas e nas observações, no intuito de buscar convergências e divergências extraídas entre as falas dos participantes e entre estas e as observações. Evidenciou-se, dessa 
maneira, a seguinte categoria: o matriciamento e suas interações entre os níveis de complexidade da rede de saúde mental.

Essa análise foi ilustrada com os discursos dos participantes da investigação. As ilustrações dispõem a reflexão que sintetiza o grupo de convergência, de divergência e de complementaridade de cada discurso dos trabalhadores da saúde pesquisados, com a finalidade de ampliar a compreensão do fenômeno.

Ressalta-se: a pesquisa é um destaque do projeto intitulado "A rede de atenção primária como elo de integração da saúde mental, com ênfase no matriciamento", financiado pelo MS/FUNCAP/CNPq. Como exigido, o projeto foi submetido à análise do Comitê de Ética em Pesquisa (CEP) da Universidade Estadual do Ceará (UECE), tendo parecer favorável, sob protocolo 08622882-0.

\section{Resultados e discussões}

Na temática do matriciamento e suas interações entre os níveis de complexidade da rede de saúde mental, pretende-se discutir o acordo estabelecido entre os diferentes atores sociais no processo de construção e fortalecimento da rede assistencial de saúde. Assim, descrevem-se a concepção dos sujeitos e os conteúdos que emergiram da observação sistemática acerca do matriciamento, a gestão sobre a dinâmica nos serviços e as tensões na busca pelo objetivo comum que é a inovação de saberes e práticas em saúde mental.

Ao refletir sobre as concepções dos trabalhadores das equipes da ESF e CAPS, respectivamente equipe de referência e equipe de apoio matricial, segundo se observa, os trabalhadores do CAPS consideram o matriciamento como articulador das ações de saúde mental nos territórios e na comunidade. Isso ao desconstruírem os modelos preestabelecidos e normativos, engessados em funções cristalizadas, para centralizar o olhar sobre o usuário e a comunidade, como possibilidade de fortalecimento de vínculos e maior qualidade de vida, como mostram os discursos convergentes a seguir:

[...] o que nós estamos tentando dizer ao fazer o matriciamento é que o paciente é do território e que a equipe de saúde mental pode prestar uma assessoria à equipe do território pra conduzir os casos, mas ele é um paciente daquele território. (Grupo I)

Elas [as equipes] quererem se integrar, saberem que são parceiras. Entender que é uma parceria. E não que eu tenho aqui o meu usuário e você tem o seu. Os usuários são de todos. (Grupo I) 
[...] esperamos que com o matriciamento os profissionais mudem o olhar e que entendam que o paciente precisa ser inserido dentro da comunidade dele, que ele consiga ter uma qualidade de vida assegurada dentro da comunidade dele, sem preconceito, sem discriminação, sem nenhum tipo de exclusão, que ele seja incluído na comunidade em que ele vive. (Grupo I)

Em corroboração a essa ideia, consoante afirmam Quinderé e Jorge (2010), ao atuar como articulador das ações de saúde mental nos territórios, o apoio matricial se responsabiliza pelas açôes que possibilitem o acompanhamento das pessoas em sofrimento psíquico em atividades individuais e coletivas, promovendo suporte aos familiares, atuando na educação em saúde e na reabilitação psicossocial dos usuários. Desse modo, à medida que os serviços e as ações de saúde mental na atenção primária vão sendo ampliados, a rede de atenção fica cada vez mais complexa.

Por sua vez, os trabalhadores da ESF do cenário II refletem a concepção de matriciamento como a possibilidade de articulação com o território, de inovação no cuidado em saúde mental, pois ele rompe com paradigmas que reduzem o usuário a objeto e se pauta num cuidado fragmentado, em busca de novos saberes e práticas em saúde mental. Assim, os recursos terapêuticos da comunidade passam a ser descobertos como possibilidade para oferta de serviços, e também como oportunidade de gerar reflexôes sobre o preconceito e estigma ainda presentes nesse contexto.

[...] eu acho que matriciamento é algo que veio exatamente para ajudar, para as pessoas em sofrimento não ficarem somente com aquele estímulo de hospital psiquiátrico e CAPS.(Grupo II)

[...] paciente fica ainda muito institucionalizado pelo CAPS e pelo hospital psiquiátrico, o atendimento de saúde mental fica focado e centralizado nesses serviços. (Grupo II)

Segundo evidenciado, consoante a observação sistemática, as equipes de referência e de apoio matricial estabelecem objetivos comuns a serem concretizados com a prática do matriciamento. Essa interação caracteriza o trabalho em rede, pois exige interdependência entre atenção primária e especializada, porquanto o vínculo com o território é maior com as equipes da ESF. Já a equipe de saúde mental descentraliza o cuidado e, desse modo, compartilha saberes e práticas, produzindo corresponsabilização pelos casos entre as equipes. Nesse sentido, a existência de redes deve envolver diferentes 
sujeitos ou organizações, vinculados entre si por estabelecimento de pactos de compartilhamento da gestão do cuidado e também na manutenção de objetivos em comum, os quais possibilitam o caminhar do usuário para o atendimento de suas necessidades de saúde (FLEURY; OUVERNEY, 2007).

Além disso, o matriciamento funciona como um dispositivo de atenção psicossocial, uma vez que abre caminhos para reflexôes sobre a inserção de pessoas com transtorno mental na comunidade. A partir daí, surge a demanda de se repensar a postura do trabalhador da ESF e da comunidade no tocante a essas pessoas. Isso se justifica, pois ainda sobressaem nos discursos sentimentos como medo, estigma e preconceito, enraizados no imaginário da sociedade em relação às pessoas com transtornos mentais. Esses sentimentos reproduzem a ideia de isolamento e de que as pessoas com transtorno mental somente podem ser acompanhadas nos serviços especializados, mesmo em cuidados que demandam assistência no âmbito da atenção básica. Esse aspecto pode estar relacionado à falta de conhecimento e ao manejo com os usuários, demonstrado empiricamente no discursos a seguir:

Com o matriciamento isso aí ajudou bastante porque quebrou alguns paradigmas. A questão mesmo do preconceito, do medo dos profissionais em tá lidando com essa situação. (Grupo II)

[...] não é que a gente não tenha interesse ou desejo de atender os pacientes de saúde mental, nós não temos tempo e acho que até falta mais formação, mais qualificação para que possamos nos sentir mais preparados. (Grupo II)

Em reforço a esse achado, como relatam Figueiredo e Onocko-Campos (2009) em estudo realizado em Campinas-SP, evidenciou-se nos resultados o quanto é marcante a expressão de angústia da equipe da atenção primária ao entrar em contato com o sofrimento, e também um determinado medo em relação à necessidade de lidar com os usuários considerados da saúde mental. Ainda nesse estudo, segundo identificou-se, a capacidade da equipe da atenção primária em acolher o sofrimento depende da disponibilidade do profissional, do seu perfil e da sua formação.

Chama-se a atenção para o seguinte fato: neste estudo, houve divergências nos dois cenários quanto à justificativa da dificuldade dos profissionais da atenção primária em realizar o matriciamento. Para determinados profissionais participantes do cenário I, a maior resistência em atender os casos de saúde mental não está associada à falta de disponibilidade de tempo e nem de qualificação, mas 
sim ao fato de que o apoio matricial é interpretado como um trabalho a mais, cujo efeito é produzir sobrecarga na dinâmica de trabalho.

\begin{abstract}
Porque alguns profissionais [da atenção primária] ainda não entendem e acham que o matriciamento veio para prejudicar, para formar uma demanda que não é dele. (Grupo I)

[...] a gente já chegou a ouvir "Vocês estão querendo passar os pacientes para cá", como se a gente não quisesse receber nos CAPS, e a gente tenta trabalhar na cultura que não, que na verdade estamos tentando discutir mais os conhecimentos sobre saúde mental e a potência da atenção primária. (Grupo I)
\end{abstract}

No que respeita ao cenário II, detectaram-se as dificuldades dos trabalhadores da saúde da APS em compreender que a atenção em saúde mental transversaliza todas as práticas de saúde, as quais integram as ações programáticas desenvolvidas nesse âmbito de atenção.

$\mathrm{Na}$ nossa unidade de saúde as equipes já precisam dar conta de muitos programas: saúde da criança, saúde do idoso [...] enfim, fica muito complicado para a equipe da atenção primária fazer o acompanhamento dos casos de saúde mental. (Grupo II)

Tais dificuldades podem estar relacionadas à compreensão de cada trabalhador sobre a organização da rede hierarquizada de serviços, que se estrutura a partir das normatizaçōes do Sistema Único de Saúde. Ou seja, o próprio Programa Saúde da Família (PSF) nasce de uma diretriz normativa e opera sob a lógica das ações programáticas, com foco no procedimento, e que impõe fortes amarras ao trabalhador (FRANCO, 2006). Dessa forma, romper com essa realidade gera reflexôes no modo de conceber a prática cotidiana dos sujeitos, que podem contribuir para ou dificultar a implementação de mudanças.

Assim, o matriciamento em saúde mental fortalece a micropolítica, compreendida como o agir cotidiano dos sujeitos, desviando o foco do procedimento para as relaçóes entre as equipes no cenário, onde elas se encontram, configurando-se como potência para abrir "linhas de fuga" para se trabalhar com "microrredes" no interior da organização (FRANCO, 2006, p. 459). Nesse caso, a gestão do cuidado vai se estabelecer a partir de linhas de cuidado que rompem com a hierarquia vertical e burocratizada, para se constituir em conexões que sejam resolutivas com base em dispositivos como o acolhimento e práticas não integrantes do sistema formal de atenção à saúde (CECIM; FERLA, 2006).

Portanto, a prática terapêutica no território se modula de maneira diferente da do consultório, construindo um trabalho junto à população local e nos serviços comunitários. A interconexão entre os serviços de saúde mental e a ESF 
evita a fragmentação dos atendimentos e facilita o planejamento das ações no território, uma vez que, no campo da saúde mental, ocorre uma complexidade invertida, pois enquanto no hospital o procedimento é mais simplificado, ele exige no território maior complexidade das açôes de saúde. Tais experiências abrem espaços para uma clínica comprometida com a vida e a subjetividade (VIEIRA FILHO; NÓBREGA, 2004).

Compondo esse trabalho comunitário, para além da clínica tradicional, o atendimento dos usuários em grupo é uma alternativa para a implementação da mudança do modelo de atenção, porquanto o espaço grupal deverá gerar um ambiente propício para a escuta, para o acolhimento e compartilhamento de sentimentos. Dessa forma, os trabalhadores dos CAPS do cenário II sugerem novas práticas, funcionando como uma retaguarda assistencial para as equipes da ESF. Entretanto, esse processo deve ser flexível e obedecer à realidade de cada espaço, de cada grupo. No discurso, observa-se uma tentativa de padronização do "estilo" do CAPS.

[...] a partir do momento que tiverem um número suficiente monta-se um grupo e ele vai toda sexta-feira, porque a nossa proposta até de CAPS é de trabalhar na comunidade, e de montar um grupo que depois vai trabalhar ao estilo do CAPS. (Grupo I)

Nesse âmbito, mediante a observação sistemática identificou-se que a dinâmica dos serviços de saúde passa por um processo de reorganização, no tocante às práticas dos trabalhadores, do acesso e do fluxo de usuários na rede de serviços por meio dos encaminhamentos.

O funcionamento em rede de serviços possibilita a atuação do trabalhador nos espaços extramuros do seu local de atendimento, indo além do consultório, da sala de espera ou mesmo da atividade em grupo no espaço do posto de saúde ou do CAPS. Essa atuação externa ao ambiente de trabalho formal contribui para a articulação dos trabalhadores entre si, ou seja, favorece a comunicação pessoal e relacional dos indivíduos, fortalece vínculos entre os trabalhadores, e a formação de redes informais de apoio. Na psicologia social, utiliza-se o termo "rede" para definir o universo relacional do indivíduo. Ela se caracteriza por seu tamanho, densidade, composição, etc. (FLEURY; OUVERNEY, 2007). Nos dois cenários estudados, os discursos dos trabalhadores dos CAPS, no que concerne, a estruturação da rede de apoio e maior conhecimento da rede formal dos serviços de saúde a partir da "saída" da instituição, sobressai essa ideia. 
[...] outra coisa interessante é a saída da instituição, essa coisa de quebrar com este atendimento só dentro da instituição, ir para outro espaço, está contribuindo com o atendimento conjuntamente em outra unidade, o CAPS tem muito esta ideia, a gente não tem esta política, a gente tem que sair para a comunidade, seja ela nos centros sociais, nos postos de saúde, onde tiver este espaço, isto ajuda bastante, e se mais profissionais estivessem se envolvendo nesta questão a gente só ia ganhar, porque isto também reflete no nosso trabalho aqui dentro do CAPS e também porque a gente tem que fazer um mapeamento constante da rede e isto só faz ganhar no nosso trabalho. (Grupo I)

Outra possibilidade apontada pelos sujeitos da pesquisa na reorganização da dinâmica dos serviços é a acessibilidade. De acordo com o conteúdo das entrevistas e a observação, há um aumento na oferta de serviços na unidade de saúde, que enseja facilidade no uso e no acesso geográfico a eles, respondendo mais rapidamente às necessidades dos usuários. $\mathrm{Na}$ rede hierarquizada, correspondente ao cenário II o tempo de espera para uma consulta demandava dias ou meses, além do problema da distância geográfica. Com as ações de saúde mental na atenção primária, esse tempo diminui, pois a ESF se estrutura de modo a ofertar o serviço no próprio território, respaldada por práticas que valorizem a integralidade, o trabalho em equipe e contemplem as necessidades dos usuários de modo integral e equitativo.

[...] a comunidade por ter alguém na família com transtorno mental ela tem mais facilidade de chegar em um posto de saúde como ela chega para qualquer área, de odontologia, de enfermagem, de um clínico, ela vai ter acesso a um psiquiatra ou alguém da equipe que possa dar acolhimento a ela e ela não chegar a um desespero porque o CAPS é longe da casa dela e se tiver alguém com referência naquele posto

[...] aí fica mais fácil para a comunidade mesmo a nível de acessibilidade, porque acaba que não é um paciente do CAPS e passa um mês para ser atendido, e na realidade lá vai ser a forma de entrada mais fácil. (Grupo II)

Em relação ao cenário I, consoante ao aspecto citado, os trabalhadores da saúde relatam que há dificuldades referentes ao acesso dos usuários ao nível de atenção primária (ESF) e secundária (CAPS). Eles argumentam que se constitui uma tarefa árdua acessar os serviços, pois não há cobertura considerável de CAPS e de unidades de saúde no município, como também da oferta da prática de matriciamento, e, assim, os usuários acabam tornando-se reféns da "síndrome da peregrinação". Esta pode ser compreendida como o transitar pelos diferentes serviços da rede sem resolubilidade das demandas manifestadas pelos usuários. 
Fundamentados em Donabedian, Travassos e Martins (2004) conceituam a acessibilidade. Segundo afirmam, esta não se restringe apenas ao uso ou não de serviços de saúde, mas inclui a adequação dos profissionais e dos recursos tecnológicos utilizados às necessidades de saúde dos pacientes. Sobre essa temática, conforme enfatizam Dimenstein et al. (2009), ainda há muitos entraves para a acessibilidade das pessoas em sofrimento psíquico ao campo da saúde mental. Como observado, as unidades básicas de saúde vêm tradicionalmente respondendo por menos de $10 \%$ da demanda, quando deveriam ser o local privilegiado de acolhimento, evitando que o hospital psiquiátrico se configure como porta de entrada para os serviços. Essa realidade confirma a dificuldade de inserção da saúde mental na atenção primária e o papel centralizador ocupado pelos CAPS e pelo hospital psiquiátrico na rede de cuidados do cenário I.

Tem uma demanda reprimida muito grave. E isso daí não dá para se resolver do dia para noite. Mas o que a gente pode fazer estamos tentando aqui na ponta. (Grupo II)

Nesse sentido, o matriciamento surge no intuito de desconstruir os caminhos burocráticos dos sistemas de referência e contrarreferência do sistema de saúde, hierarquicamente organizados. Ele desconstrói a lógica dos encaminhamentos verticalizados quando insere trabalhadores de um nível em outro, permitindo capacitação das equipes básicas e assistência integral em vários níveis ao mesmo tempo.

Em seguimento a essa discussão, segundo se evidencia, para os participantes do estudo, a prática do matriciamento possibilita o início de uma mudança no fluxo burocrático e hierárquico de usuários na rede e na lógica dos encaminhamentos dos casos atendidos na ESF e nos serviços de saúde mental. Isso pode ser compreendido por haver uma aproximação entre os trabalhadores desses serviços, facilitando a comunicação e a interação entre eles, tornando referência e contrarreferência personalizadas. Transcende-se, assim, o método tradicional do encaminhamento restrito e descompromissado, consoante se depreende do discurso a seguir:

[...] o que eu percebo sobre o matriciamento é com relação aos encaminhamentos, hoje tem mais segurança nestes encaminhamentos, tanto do CAPS quando direciona pacientes para os postos, porque a gente conhece o pessoal que trabalha nos postos a gente já percebe este retorno, e uma coisa positiva é que antes era muito, "fulano que falava com cicrano que consegui isto". Hoje a gente já percebe que é uma coisa 
de instituição para instituição, de serviço para serviço, é mais formalizada. Também quando vem um paciente para o CAPS que foi encaminhado pelos postos, eu já sei quem foram os profissionais que atenderam, fica mais fácil de a gente trabalhar em conjunto, e esta rede ela vai se fechando mais, isto é uma coisa que é muito interessante, diminui já os encaminhamentos sem necessidade. (Grupo I)

Bezerra e Dimenstein (2008), em estudo desenvolvido em Natal-RN, dentre os resultados, destacam que uma das propostas do matriciamento é ampliar as ações de saúde mental para a rede básica, superando a lógica dos encaminhamentos e de referência e contrarreferência. Ele traz, portanto, resolubilidade para as demandas a partir de um trabalho compartilhado pelas equipes da atenção primária e dos serviços especializados em saúde mental.

Conforme os dados empíricos revelam, nos cenários pesquisados ocorreu essa ampliação, aquecida com a parceria entre CAPS e ESF. Sobretudo na ESF, há um reconhecimento dos trabalhadores de que o matriciamento favorece a comunicação entre os serviços, ao funcionar como um arranjo de gestão do cuidado que traz para eles segurança à medida que eles implementam um novo olhar ao usuário, utilizando tecnologias leves como a escuta de suas necessidades e o vínculo.

Ajudou também um pouco na questão da parceria entre CAPS e ESF. Porque antes funcionava muito e somente na questão do encaminhamento e às vezes não se conhecia esse profissional que tá atendendo lá no CAPS e agora com essa metodologia de trabalho do matriciamento permitiu que os profissionais se conhecessem melhor e isso traz mais segurança, traz mais conforto nessa questão da conduta perante o usuário que está ali necessitando. (Grupo II)

Entretanto, na prática, a observação sistemática revelou a dificuldade de algumas equipes no concernente à corresponsabilização dos projetos terapêuticos dos usuários. Sobressai o momento quando a equipe de apoio matricial chegou à unidade de saúde da família e não encontrou profissionais disponíveis para as atividades de matriciamento, geralmente agendadas semestralmente, uma vez por semana para cada unidade de saúde. Desse modo, o atendimento previsto para ser em conjunto ficava a critério da equipe do CAPS, a qual se respaldava no discurso de que os delineamentos dos casos deveriam ser feitos com a equipe multiprofissional e interdisciplinar, e ainda que, na própria concepção de matriciamento, a corresponsabilização é uma característica essencial, desviando-se do modelo da consulta ao especialista, fragmentado e centrado no procedimento, conforme pode ser corroborado nos discursos a seguir: 
Às vezes acontece do profissional do CAPS chegar aqui e não ter nenhum profissional

pra acompanhar e isso daí quebra um pouco o processo porque acaba virando como se fosse um encaminhamento, apenas usuário ir até profissional e profissional vir até ele. Porque ele diz que não pode tomar conduta só, precisa ter a equipe ali para se corresponsabilizar e isso é uma grande dificuldade. É algo que a gente ainda tem que aprender, que botar mesmo em prática essa participação mais ativa das equipes. (Grupo II)

Na prática ele [o matriciamento] está acontecendo. A gente está encaminhando o paciente do PSF, sobre o qual, assim, o médico tem alguma dúvida de como é, de como comandar o tratamento e aí a gente manda pro matriciamento. (Grupo II)

Dessa maneira, observa-se que há divergências entre os discursos dos sujeitos e os conteúdos oriundos da observação sistemática, pois alguns permeiam uma dimensão teórica sobre a prática, mediante o reconhecimento do matriciamento como um arranjo potente de ampliação do olhar dos trabalhadores diante das demandas de saúde mental na ESF. Outros, porém, referem que, na prática, verifica-se a resistência de alguns profissionais em participar das atividades para implementação do matriciamento nos cenários estudados. Em geral, os sujeitos ressaltam a importância do matriciamento, uma vez que as ações de saúde mental estão sendo ampliadas na rede de atenção primária, explorando e investindo nos recursos da própria comunidade no território, porquanto os serviços dos CAPS são insuficientes para a demanda em saúde mental. Com isso, a atenção primária assume um papel fundamental na ampliação da cobertura em saúde mental, ao contribuir para a melhoria do acesso dos usuários aos serviços.

Nesse sentido, os discursos dos trabalhadores da saúde do cenário I revelam complementaridade quando se referem às dificuldades enfrentadas pelos trabalhadores da rede de serviços. Os sujeitos enfatizam a necessidade de maior articulação entre os CAPS, a atenção primária e outros serviços da rede formal de saúde. Outra dificuldade diz respeito à falta de integração entre os serviços, e também ao reconhecimento da rede formal e não formal pelo trabalhador da saúde, o que perpassa também pela falta de informação dos fluxos de atendimento e o caminhar do usuário nas linhas de cuidado, conforme se evidencia a seguir:

[...] a gente sabe que muitas pessoas que chegam até o CAPS não precisam estar aqui, se cria um rótulo, uma institucionalização sem ter necessidade, tanto é que a gente busca trabalhar muito com a rede, não só com os postos, mas com tudo que tem dentro da comunidade que auxilia, que são as comunidades terapêuticas, que algumas comunidades têm, como a da universidade, como por exemplo, o encontro das igrejas. Então estes mecanismos a gente tenta acionar para auxiliar, e uma das dificuldades é esta resistência por parte das equipes.(Grupo I) 
Ainda falta uma melhor integração dessas equipes. Ainda falta as pessoas se conhecerem mais. Conhecer um pouco como é que funcionam os dois serviços. Saber o que é que a rede dispõe. O que a rede tem disponível para oferecer para o usuário. Saber o que encaminhar. Porque às vezes os profissionais não sabem nem como é que funciona o serviço. Quais são os casos, as pessoas que a gente acompanha. Falta um esclarecimento maior dessas equipes. Da mesma forma a equipe do CAPS também tem que saber como é que funciona a demanda de trabalho, o fluxo de trabalho da atenção primária. Falta um maior esclarecimento e uma maior integração dessas equipes. (Grupo I)

Também por conta da falta de comunicação entre a equipe da atenção secundária e a equipe da atenção primária, essa comunicação ainda não foi fortalecida, esse vínculo ainda entre as equipes. Essa parceria ainda não foi muito bem estruturada. E eu acho que a dificuldade maior está aí, nas dificuldades que as equipes têm de atender essas pessoas de saúde mental. Acabam achando mesmo que é função do CAPS, da atenção secundária ficar com essa demanda. E também a comunicação. A gente esbarra nesse problema de comunicação entre as equipes, no fortalecimento de vínculo entre as equipes. (Grupo I)

Diante de tais dificuldades, é preciso reconhecer, ainda, a qualidade do atendimento ofertado, identificar quais são as práticas de saúde produzidas, ou seja, quais estratégias podem ser efetivadas pelos serviços de atenção primária para que essa demanda em saúde mental encontre resolubilidade na própria unidade de saúde e, quando não, que seja possível recorrer aos serviços da rede de saúde mental. Nesse sentido, afirma-se: o matriciamento se configura como um suporte técnico especializado que é ofertado a uma equipe interdisciplinar de saúde com vistas a ampliar seu campo de atuação e a qualificar suas ações, contribuindo para o aumento da capacidade resolutiva das equipes, qualificandoas para uma atenção ampliada em saúde que contemple a totalidade da vida dos sujeitos (FIGUEIREDO; ONOCKO-CAMPOS, 2009).

Os profissionais da saúde dos cenários investigados apontam também para a necessidade urgente de se repensar a formação de uma rede social e a função dos CAPS nesta, bem como de reavaliar o lugar por eles exercido no funcionamento do serviço. Inegavelmente, os CAPS vêm participando de forma efetiva do processo de implementação do matriciamento, no intuito de poder pensar a reorganização e redefinir o fluxo na rede e não atuar de forma hierarquizada, verticalizada e fragmentada. Nesse prisma, o matriciamento se configura como um elo entre a atenção primária e os CAPS, tendo em sua essência o compartilhamento de experiências e de saberes, a corresponsabilização dos casos, buscando oferecer múltiplos caminhos. Assim, o usuário poderá optar pelo percurso que considerar mais viável e resolutivo, como se identifica empiricamente no discurso a seguir: 
[...] paciente nem é do CAPS, nem do posto, ele é de todos nós [...] ele deve ter acesso

a um atendimento em toda a rede, no serviço mais próximo dele e onde for o mais indicado para seu caso.(Grupo I)

Sobre o supracitado, Dimenstein et al.(2010) afirmam que os serviços de saúde mental muitas vezes são utilizados como um espaço de lazer, socialização e diversão. Sendo assim, nota-se que os usuários não estão vinculados a outros serviços de saúde, nem a outros espaços sociais, mantendo-se no restrito circuito casa-serviço-casa. Isso indica que, além das demandas de acompanhamento e seguimento psiquiátrico, as quais poderiam continuar a ser atendidas no serviço de saúde mental, esses usuários necessitam circular em outras redes capazes de dar suporte às suas diversas necessidades de saúde e socialização.

$\mathrm{Na}$ ótica de Jorge et al. (2006), a construção da assistência no CAPS, bem como da rede de serviços substitutivos, deve ir "além dos muros" destes, os quais são limitados, muitas vezes, por paredes e espaços diminutos. Corrobora-se essa posição. Ademais, para isso, os profissionais inseridos no matriciamento devem estar conscientes de que a atuação na promoção da saúde mental perpassa por um olhar voltado para o sujeito em toda sua complexidade, sendo necessária a formação de uma rede social.

Ante o contexto explicitado, considera-se que o matriciamento funciona como articulador das ações no cerne da macrorrede do SUS. Não seria uma rede separada da grande rede de serviços, mas, prioritariamente, deve funcionar em interlocução com os vários serviços de saúde, os quais precisam interconectar-se com os múltiplos setores inseridos no território.

\section{Considerações finais}

Segundo revelou a análise das entrevistas e das observações no campo, a articulação por meio do matriciamento em saúde mental e dos demais serviços integrantes da rede de atenção se impõe como algo relevante para os atuais gestores, implicando transformações profundas nas práticas institucionalizadas. Evidentemente, existem os limites decorrentes, sobretudo, da própria determinação do cotidiano múltiplo, diverso e dinâmico presente no setor.

Diante dos resultados, ressalta-se: o matriciamento é uma importante ferramenta de reorganização do fluxo da atenção à saúde mental em rede, sendo uma prioridade no sentido de se produzir cuidado integral, contínuo 
e de qualidade às pessoas em sofrimento psíquico. Isso porque possibilita a construção de um acompanhamento terapêutico não limitado às fronteiras de um dado serviço, mas diluído em diversas instâncias, articulado por uma equipe de referência. Portanto, mobiliza inúmeros atores para lidar com o andamento do caso, e, assim, propicia um cardápio amplo de estratégias, que enriquece e viabiliza a articulação de redes de cuidados.

Como pode ser depreendido, a criação de uma rede de atenção integral à saúde mental deve ser formada por diversos dispositivos, substitutivos à lógica manicomial, tais como CAPS, ambulatório especializado, internação em hospital geral, serviços residenciais terapêuticos e atenção nas unidades básicas de saúde. Além do mais, essa rede deve buscar articulação com os dispositivos de áreas diversas, como a cultura, a justiça, a habitação, entre outros.

Contudo, reafirma-se a importância do debate sobre o apoio matricial, bem como sobre outras estratégias possíveis para tecer uma rede de atenção capaz de fazer a articulação e a interligação entre os serviços integrantes da saúde mental e os demais disponíveis no território. Mais do que uma forma de estruturar a rede de saúde mental, o apoio matricial pode ser pensado como uma forma de fazer saúde e de estruturar a rede de saúde pública como um todo.

\section{Referências}

BEZERRA, E.; DIMENSTEIN, M. Os CAPS e o trabalho em rede: tecendo o apoio matricial na atenção básica. Psicol. cienc. prof, v. 28, n. 3, p. 632-645, set. 2008.

BRASIL. Ministério da Saúde. Coordenação de Saúde Mental/Coordenação de Gestão da Atenção Básica. Saúde Mental e Atenção Básica: o vínculo e o diálogo necessários. Brasília: Ministério da Saúde, 2003.

- Ministério da Saúde. Secretaria de Atenção à Saúde. Departamento de Ações Programáticas Estratégicas. Departamento de Atenção Básica. Coordenação Geral de Saúde Mental. Coordenação de Gestão da Atenção Básica. Normas para pesquisa envolvendo seres humanos (Res. CNS 196/96 e outras). Brasília: Conselho Nacional de Saúde, Comissão Nacional de Ética em Pesquisa - CONEP, 2000. (Série Cadernos Técnicos).

CAMPOS, G.W.S. Equipes de referência e apoio especializado matricial: um ensaio sobre a reorganização do trabalho em saúde. Cien. Saúde Colet., v. 4, n. 2, p. 393-403, 1999.

CAMPOS, G.W.S.; DOMITTI, A.C. Apoio matricial e equipe de referência: uma metodologia para gestão do trabalho interdisciplinar em saúde. Cad. Saúde Pública [online], v. 23 , n. 2, p. 399- $407,2007$. 
CECCIM, R.B., FERLA, A.A. Linha do cuidado: a imagem da mandala na gestão em rede de práticas cuidadoras para uma outra educação dos profissionais da saúde. In: PINHEIRO, R.; MATTOS, R.A. (Orgs.). Gestão em redes: práticas de avaliação, formação e participação na saúde. Rio de Janeiro: Cepesc, 2006.

DIMENSTEIN, M. et al. O apoio matricial em Unidades de Saúde da Família: experimentando inovações em saúde mental. Saúde soc. [online], v. 18, n. 1, p. 63-74, 2009. DIMENSTEIN, M. et al. Estratégia da atenção psicossocial e participação da família no cuidado em saúde mental. Physis: Revista de Saúde Coletiva, Rio de Janeiro, v. 20, n. 4, p. 1209-1226, 2010.

FIGUEIREDO, M.D. Saúde Mental na Atenção Básica: um estudo hermenêutico-narrativo sobre o apoio matricial na Rede SUS-Campinas. Campinas, 2006.

FIGUEIREDO, M.D.; ONOCKO-CAMPOS, R. Saúde Mental na atenção básica à saúde de Campinas, SP: uma rede ou um emaranhado?. Ciênc. saúde coletiva [online], v. 14, n. 1, p. 129-138, 2009.

FLEURY, S.; OUVERNEY, A.M. Gestão de redes: a estratégia de regionalização da política de saúde. Rio de Janeiro: FGV, 2007.

FRANCO, T.B. As Redes na Micropolítica do Processo de Trabalho em Saúde.In: PINHEIRO, R.; MATTOS, R.A. (Orgs.). Gestão em redes: práticas de avaliação, formação e participação na saúde. Rio de Janeiro: CEPESC, 2006.

INPES, G. Psychiatrie et santé mentale: 2005-2008.Orientations au service: politique publique de psychiatric et de santé mentale. Paris, 2007.

JORGE, M.S.B. et al. Reabilitação Psicossocial: visão da equipe de Saúde Mental. Rev. bras. enferm. v. 59, n. 6, p. 734-739, 2006.

MINAYO, M.C.S. O desafio do conhecimento: pesquisa qualitativa em saúde. São Paulo: Hucitec, 2008.

ONOCKO-CAMPOS, R. T.; FURTADO, J. P. Entre a saúde coletiva e a saúde mental: um instrumento metodológico para avaliação de rede de Centros de Atenção Psicossocial (CAPS) do Sistema Único de Saúde. Cad. Saúde Pública, Rio de Janeiro, v. 22, n. 5, p. 1053-1062, maio 2006.

QUINDERÉ, P.H.D. Atenção à saúde mental no município de Sobral-CE: Interações entre os Níveis de Complexidade, Composição das Práticas e Serviços. Dissertação apresentada ao Curso de Mestrado Acadêmico em Saúde Pública da Universidade Estadual do Ceará, Fortaleza, 2008.

QUINDERÉ, P.H.D.; JORGE, M.S.B. (Des)Construção do Modelo Assistencial em Saúde Mental na Composição das Práticas e dos serviços. Saúde e Sociedade. [online], v. 19, n. 3, p. 569-583, 2010. 
STARFIELD, B. Primary care: concept, evaluation and policy. New York: Oxford University Press, 1992.

TRAVASSOS, C.; MARTINS, M. Uma revisão sobre os conceitos de acesso e utilização de serviços de saúde. Cad. Saúde Pública [online], v. 20, supl. 2, p. S190-S198, 2004.

TURATO, E.R.; FONTANELLA, B.J.B.; RICAS, J. Amostragem por saturação em pesquisas qualitativas em saúde: contribuições teóricas. Cad. Saúde Pública, v. 24, n. 1, p. 17-27, 2008.

VIEIRA FILHO, N.G.; NÓBREGA, S.M. A atenção psicossocial em saúde mental: contribuição teórica para o trabalho terapêutico em rede social. Rev. Estudos de Psicologia, Universidade Federal do Rio Grande do Norte, Natal, v. 9, n. 2, p. 373-379, 2004.

\section{Nota}

${ }^{1} \mathrm{O}$ estudo é um destaque do projeto "A rede de atenção primária como elo de integração da saúde mental, com ênfase no matriciamento", financiado pelo MS/FUNCAP/CNPq. 


\section{Abstract}

Building the mental health care network with the matrix support tool

This study aimed to analyze the matrix support as an organizer tool of mental health care network. This is a qualitative survey, conducted in Brazilian Northeast, from March to April 2010. Systematic observations and semi-structured interviews were conducted with 47 health professionals from the Family Health Strategy and Psychosocial Care Centers. The collected information was organized and analyzed by content analysis. Pursuant to the requirements, the study was submitted to the Research Ethics Committee for adapting to the standards of research involving human beings. The results showed the matrix support as a powerful strategy since it enables the construction of a linkage in SUS network services, not limited to the borders of a specific service. Also, it is interconnected by a team of reference, which mobilizes different actors to deal with the progress of the case. Thus, matrix support signals pathways that enable the connection of mental health care networks.

Key words: Primary care; continued health care network; mental health. 